\title{
Heart failure self-care interventions to reduce clinical events and symptom burden
}

This article was published in the following Dove Press journal:

Research Reports in Clinical Cardiology

23 September 2014

Number of times this article has been viewed

\section{Mary H McGreal' \\ Maureen J Hogan' \\ Colleen Walsh-Irwin' \\ Nancy J Maggio ${ }^{2}$ \\ Corrine $Y$ Jurgens 1}

'School of Nursing, Stony Brook University, Stony Brook, NY, USA;

${ }^{2}$ School of Nursing, Farmingdale State

College, Farmingdale, NY, USA
Correspondence: Corrine Y Jurgens Stony Brook University, School of Nursing, HSCL 2-246, Stony Brook, NY I I 794-8420, USA

$\mathrm{Tel}+\mathrm{I} 63 \mid 4443236$

Fax + I 63| 4443136

Email corrine.jurgens@stonybrook.edu
Background: Lack of adherence to prescribed therapies and poor symptom recognition are common reasons for recurring hospitalizations among heart failure (HF) patients. The purpose of this literature review is to examine the effectiveness of HF self-care interventions in relation to clinical events and symptom burden.

Methods: A systematic review of randomized controlled trials with a HF self-care measure was conducted. The PubMed, CINAHL, and Medline databases were searched between 2010 and 2014, using the keyword "heart failure" in combination with the terms "self-care", "self-management", "self-care maintenance", "self-care confidence", "symptoms", and "hospitalizations". Outcomes of interest were clinical events and/or symptom burden.

Results: Nine studies met the inclusion criteria. HF education was the core of all interventions examined. Dose and strategies varied across studies. All interventions that effectively decreased clinical events included education on how to respond to worsening HF symptoms.

Conclusion: Knowledge alone does not improve HF self-care behaviors or reduce the risk of clinical events and/or symptom burden. Interventions that augment self-confidence or selfefficacy to perform optimal self-care management and self-care maintenance may be useful.

Keywords: heart failure, self-care, self-management, self-care maintenance, self-care confidence, symptoms, hospitalizations

\section{Introduction}

Heart failure (HF) is a major public health concern worldwide in terms of morbidity, mortality, and cost. Currently, an estimated 5.8 million Americans are diagnosed with HF, with associated costs estimated at over $\$ 30$ billion dollars annually. ${ }^{1}$ The incidence of $\mathrm{HF}$ increases with age, and the prevalence of $\mathrm{HF}$ is predicted to increase by $46 \%$ by 2030 . Despite advances in pharmacological and medical management, mortality rates remain high, with $50 \%$ of patients dying within 5 years of diagnosis. ${ }^{1}$ In terms of morbidity, HF is responsible for more than one million hospitalizations annually. Importantly, many hospitalizations are for symptom management and considered preventable. ${ }^{2}$ Efforts to decrease hospitalization risk include providing guideline-based treatment which involves maximizing pharmacotherapy and improving self-care. ${ }^{3}$

Patients with HF require education in order to adapt to their chronic condition and perform self-care behaviors. Despite receiving HF education and perceiving HF information as important, patients often have low levels of knowledge and lack a clear understanding of the causes of $\mathrm{HF}^{4,5}$ Similarly, patients with HF often do not understand how and when self-care behaviors should be performed. ${ }^{6}$ The most favorable strategy for promoting HF self-care should be straightforward, standardized, 
and practical for a variety of health care providers and patient populations. $^{7}$

Self-care strategies are a vital link empowering patients to take responsibility for their health. Consequently, self-care strategies are patient-centric as opposed to provider-centric. ${ }^{8}$ It is important to note that terminology related to self-care varies across the literature. For the purpose of this review, operational definitions of self-care are based on the work by Riegel and Dickson. ${ }^{9}$ Accordingly, self-care encompasses self-care maintenance and self-care management behaviors that are moderated by self-care confidence. ${ }^{9-11}$ Self-care maintenance is defined as daily activities that maintain clinical stability. Typically, these are adherence behaviors, such as taking medications, limiting dietary sodium, and daily monitoring of symptoms and weight. Self-care management involves recognizing a change in symptoms and responding to this change by taking an extra diuretic, limiting fluids, or calling one's health care provider. Self-care confidence is the belief in one's ability to perform self-care behaviors effectively. Although self-care confidence is an important determinant of self-care, it is not self-care per se., ${ }^{9,11}$ Symptom monitoring is a challenge for HF patients. In particular, determining the meaning or importance of symptoms and differentiating HF symptoms from other comorbid illnesses is difficult for patients. ${ }^{12,13}$ For example, early symptoms signaling impending decompensation (eg, increasing fatigue and weight gain) are not specific to the syndrome, and only $33 \%$ of patients weigh themselves frequently or always. ${ }^{14}$ Patients also commonly attribute these symptoms to less threatening illness, and symptoms may increase insidiously, impeding early recognition. ${ }^{4,13}$ Timely reporting of symptoms and or self-management can lead to early intervention, improving quality of life and decreasing hospitalization risk. ${ }^{7}$

Effective management of HF is a major challenge for both HF patients and their health care providers for several reasons. Patients with HF are generally older in age and often have complex comorbid illness profiles. As a result, polypharmacy related to both HF and comorbid illnesses further complicate management by providers and the patient's ability to achieve effective self-care. ${ }^{15,16}$ In addition, cognitive dysfunction is common among patients with HF, potentially affecting self-care capacity. ${ }^{17-19}$ Published HF guidelines emphasize the importance of self-care behaviors to decrease clinical events requiring hospitalization. ${ }^{3,20}$ Consequently, the importance of HF patients using self-care strategies to maintain and manage their illness is critical.

Limitations of prior HF reviews include inconsistent differentiation of self-care maintenance versus self-care management, inclusion of telehealth studies, and omission of outcomes (eg, symptom burden and clinical events). .,21,22 $^{2}$ Self-care maintenance behaviors are important to maintain clinical stability, but when employed alone are insufficient in preventing clinical events such as hospitalization. ${ }^{23-26} \mathrm{In}$ addition, HF management decisions using telehealth is not the equivalent of self-care management as providers rather than patients are managing the illness. Symptom burden and clinical events were not included as outcome measures in the review by Barnason et al. ${ }^{21} \mathrm{~A}$ review by Ditewig et al examined the effectiveness of self-management interventions with regard to clinical events and quality of life. Although the authors reported a positive if not always significant improvement in clinical events and quality of life, some studies in the review were not true self-management interventions. ${ }^{8}$ As symptoms drive health care utilization, interventions that address skill in self-management of symptoms are needed to avert hospitalization. Therefore, the purpose of this review was to identify effective HF self-care management interventions that decrease clinical event risk and reduce symptom burden.

\section{Methods}

A systematic review of randomized controlled trials was conducted. ${ }^{27-29}$ Electronic databases (PubMed, CINAHL, and Medline) were searched using the key word "heart failure" in combination with the terms "self-care", "self-management", "self-care maintenance", "self-care confidence", "symptoms", and "hospitalizations". A hand search was conducted on studies retrieved. The inclusion criteria were: randomized controlled trials with a HF self-care measure, specific self-management component in the intervention, reported outcomes of interest which were clinical events and/or symptom burden, and studies published in English for the years 2010-2014. Clinical events were defined as unplanned contact with health care providers, emergency department admission, and hospitalization. Years were limited as prior reviews examined self-care interventions published for years 1996-2010. ${ }^{8,21,22}$ Intervention studies targeting selfcare knowledge alone were excluded because our outcome of interest focused on actual self-care behaviors. The authors reviewed abstracts followed by a full text review to support the reliability and validity of studies selected for the review. Consensus was reached among the authors on studies selected for inclusion. Two hundred and seventy citations were evaluated for inclusion. Duplicate citations ( $\mathrm{n}=29)$, nonrandomized clinical trials, studies that did not address self-care behaviors or outcomes of interest, and studies not available in English 
were excluded ( $n=232$; Figure 1). Nine studies $(n=1,415$ participants) met the inclusion criteria for this review.

\section{Results}

\section{Self-care interventions and clinical events}

Eight of the nine randomized trials meeting the inclusion criteria reported on the relationship between self-care management and clinical events (Table 1). Interventions varied across studies in relation to educational content, educational dose, and timeframe to event. Most of the studies used written materials such as a HF booklet. ${ }^{7,30-33}$ One investigator also created an audiotape of the HF education session for participants ${ }^{30}$ and one provided a DVD on HF self-management. ${ }^{33}$ All but one study specified use of one-on-one education. ${ }^{7,30-36}$ Instrumental support included provision of weight scales, ${ }^{7,30-33}$ pill boxes and measuring cups ${ }^{30}$ and a telemonitoring system with weight and blood pressure capability. ${ }^{36}$ Monitoring and reinforcement of education was done with follow-up telephone calls, ${ }^{30,31,33-35}$ home visits, ${ }^{7,35}$ and daily symptom and weight diaries. ${ }^{7,34,35}$ Few studies specified teaching patients in use of extra diuretic doses for worsening symptoms. ${ }^{7,31,34}$ Most studies limited the self-management component to recognizing and responding to worsening symptoms by contacting health care providers. Interestingly, six of eight studies reported improved self-care or knowledge scores, ${ }^{7,30-32,35,36}$ but only three studies reported a significant decrease in clinical events. ${ }^{32-34}$

The dose of the intervention did not consistently relate to frequency of clinical events. Among the interventions effective in reducing clinical events, the number of contacts

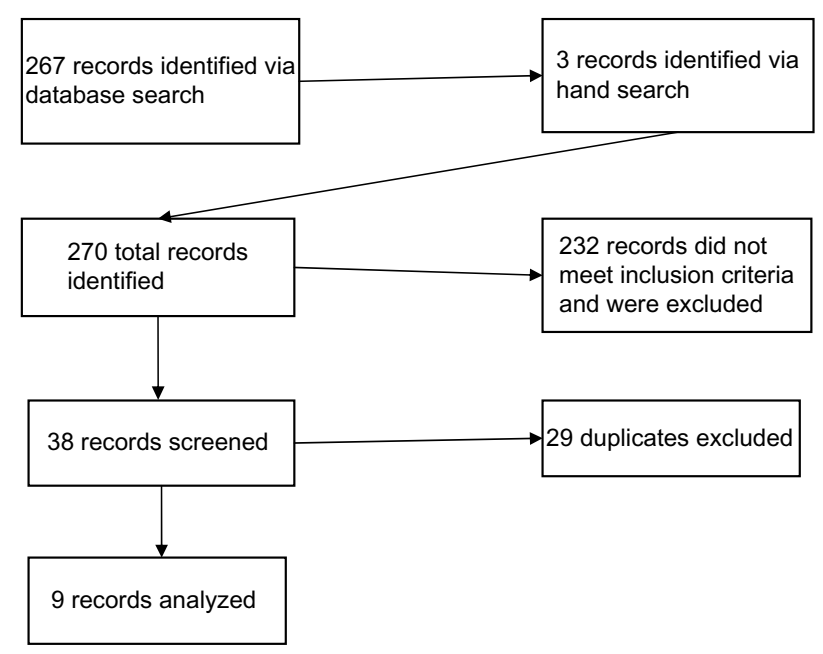

Figure I PRISMA flowchart for selection of evidence.

Abbreviation: PRISMA, Preferred Reporting Items for Systematic Reviews and Meta-Analyses. ranged from a one-time one-hour educational session ${ }^{32}$ to six contacts. ${ }^{33,34}$ The study by Kommuri et al had the largest sample $(\mathrm{n}=265)$ and the shortest intervention (one hour). ${ }^{32}$ The interventions in the studies by Lee et al and Shively et al used six sessions either in-person or by telephone. ${ }^{33,34}$ Lee et al instructed participants $(n=44)$ in use of a symptom diary, evaluation of symptoms as clusters, and how to weigh themselves daily. ${ }^{34}$ Risk for a clinical event was higher in the usual care group at the 90-day follow-up (hazards ratio $3.17,95 \%$ confidence interval 1.09-9.16). The intervention (symptom graph, symptom clusters, weighing instructions) was similar to that used by Jurgens et al that did not reduce events at 90 days. ${ }^{7}$ The interventions differed in dose. Lee et al conducted five booster sessions via telephone over 90 days, whereas Jurgens et al used one home visit to reinforce the education. Shively et al employed a patient activation intervention which addressed information, motivation, and behavioral skills necessary for self-management. Participants received a tailored education intervention based on their level of activation and self-selected goals. Participants also received instrumental support, including a blood pressure cuff, a pedometer, and a weight scale along with the DVD and booklet. Shively et al reported fewer hospitalizations in the low activation and high activation groups, but not the medium activation group..$^{33}$ All interventions that effectively decreased clinical events included education on how to respond to worsening HF symptoms.

The intervention dose ranged from one contact to nine contacts in studies reporting little or no effect on clinical events. ${ }^{7,30,31,35,36}$ The study by De Walt et al $(\mathrm{n}=605)$ reported that a multisession intervention did not decrease clinical events over 12 months compared with a single session (incidence rate ratio $1.01,95 \%$ confidence interval $0.83-1.22) .{ }^{31}$ However, the multisession intervention was beneficial in reducing HF-related hospitalizations for participants with low literacy. The usual care group received a single education session on salt avoidance and medication adherence, in addition to an educational manual and digital weight scale. The intervention group received usual care plus specific instructions on daily weights, diuretic self-adjustment, and five to eight follow-up telephone calls over 4 weeks. All participants in the study by Jurgens et al similarly received educational booklets and weight scales, which potentially blunted identification of differences in clinical events between the usual care and intervention groups. ${ }^{7}$ Seto et al reported no difference in number of clinical events among intervention group participants who received an individual educational session and a telemonitoring system to 

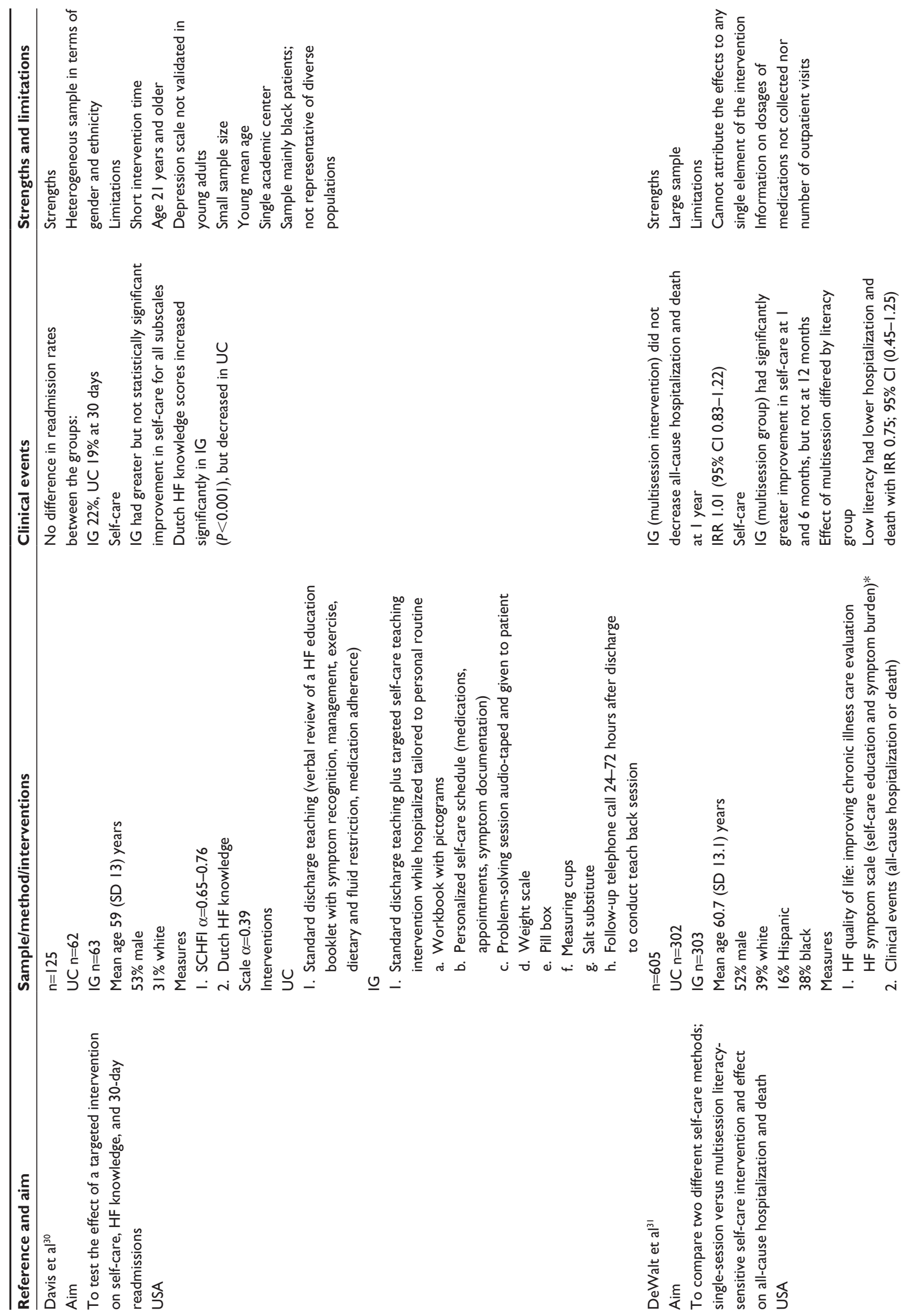

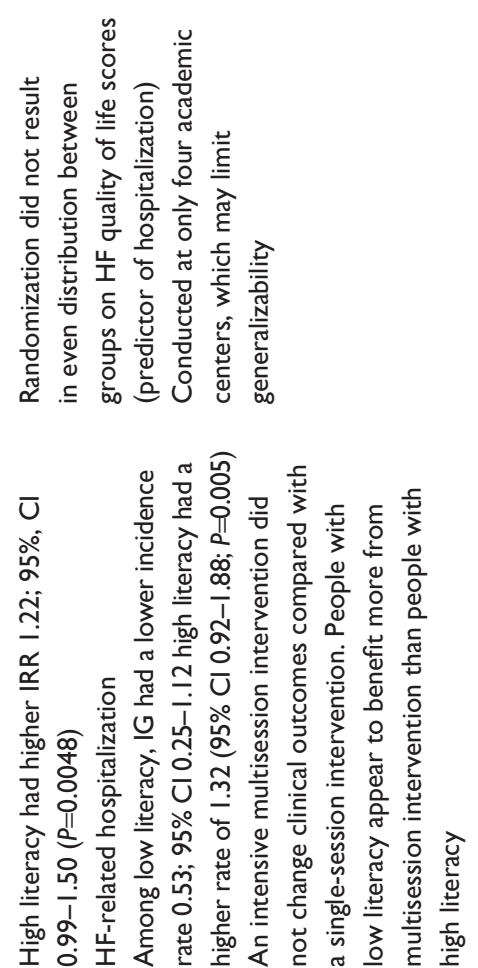
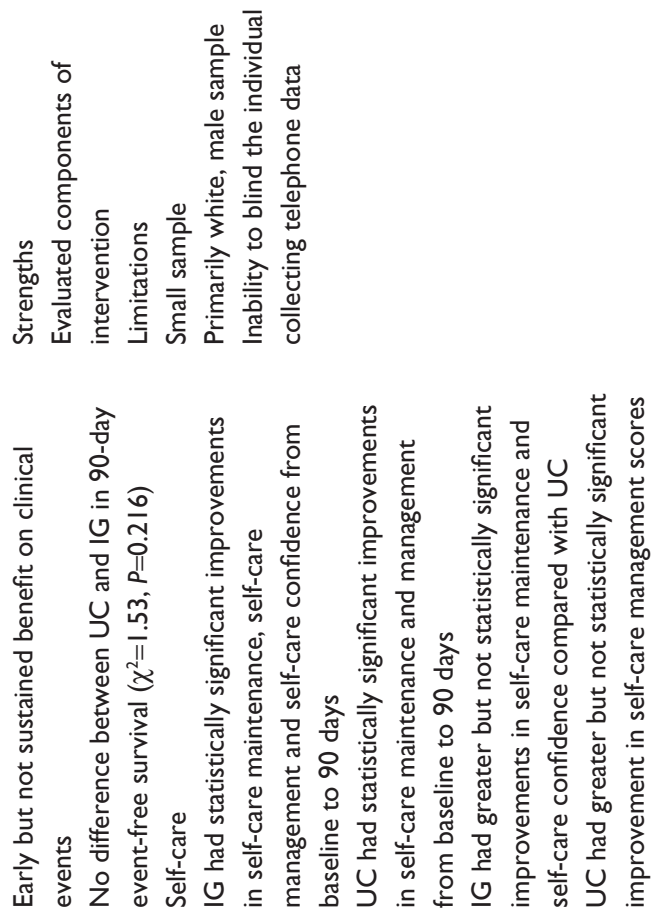
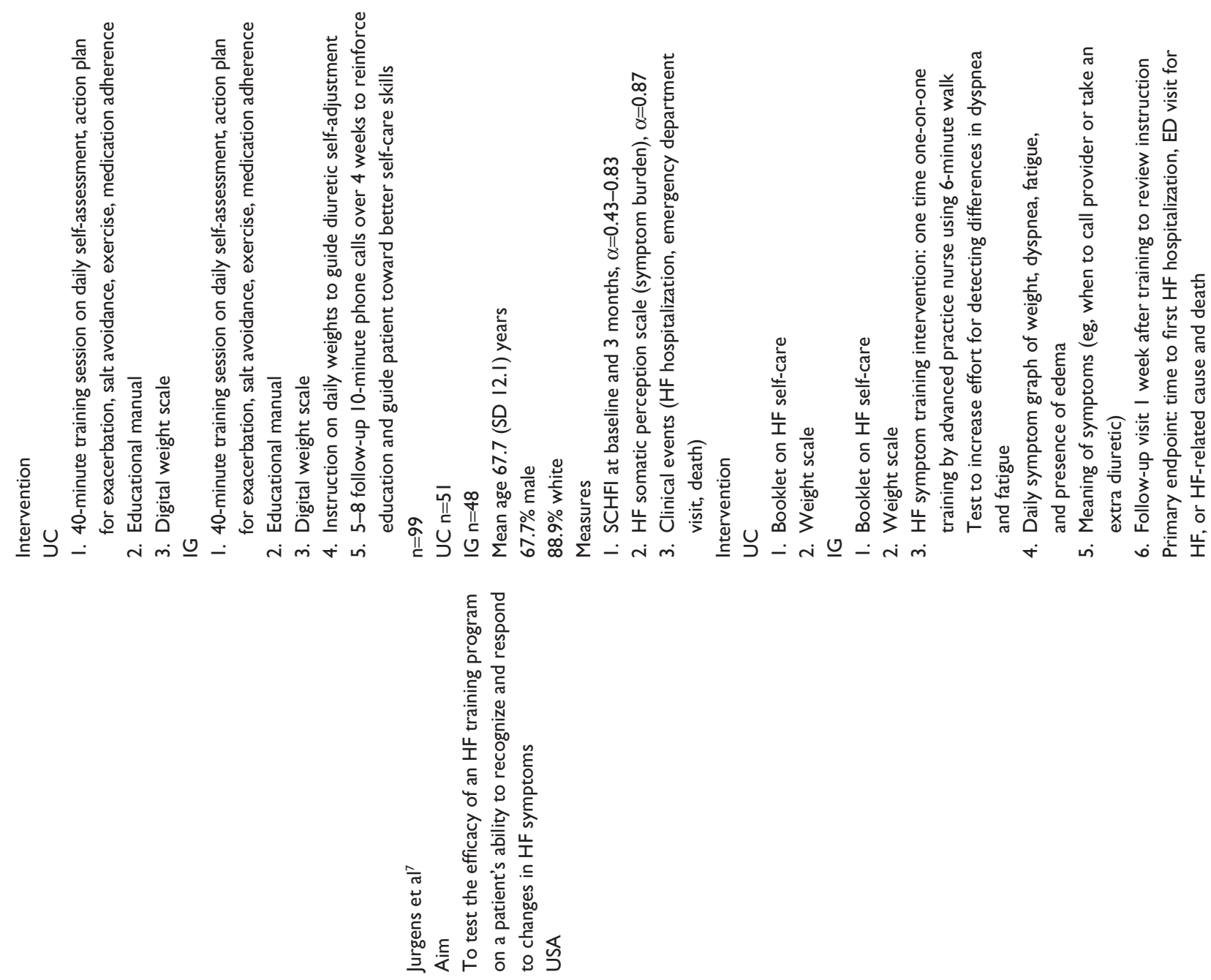

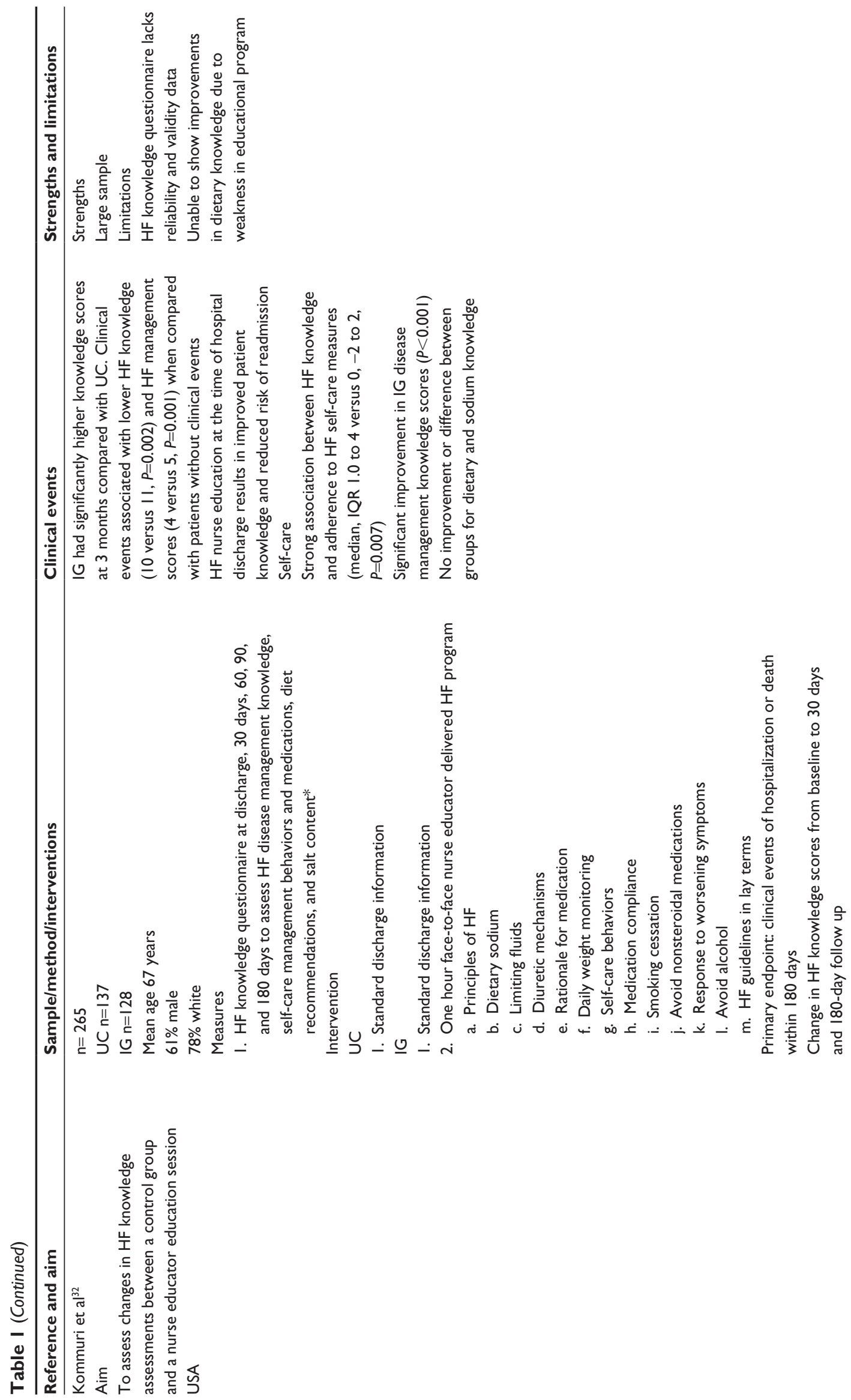


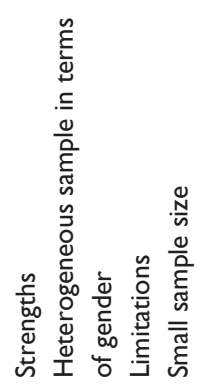

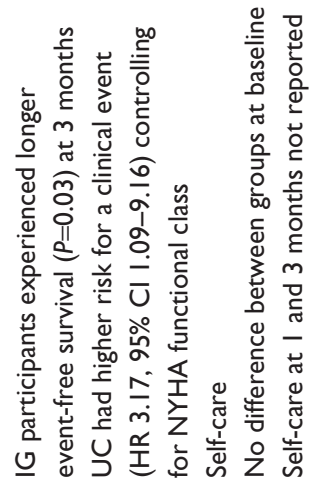

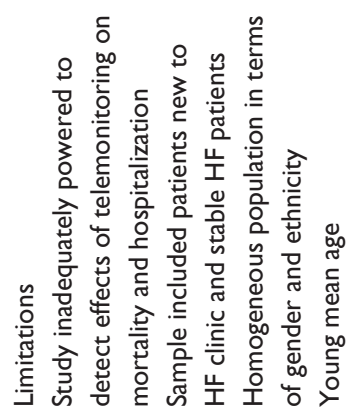

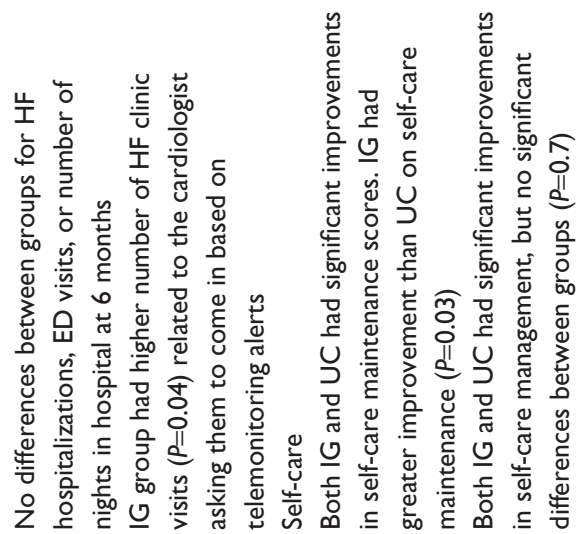

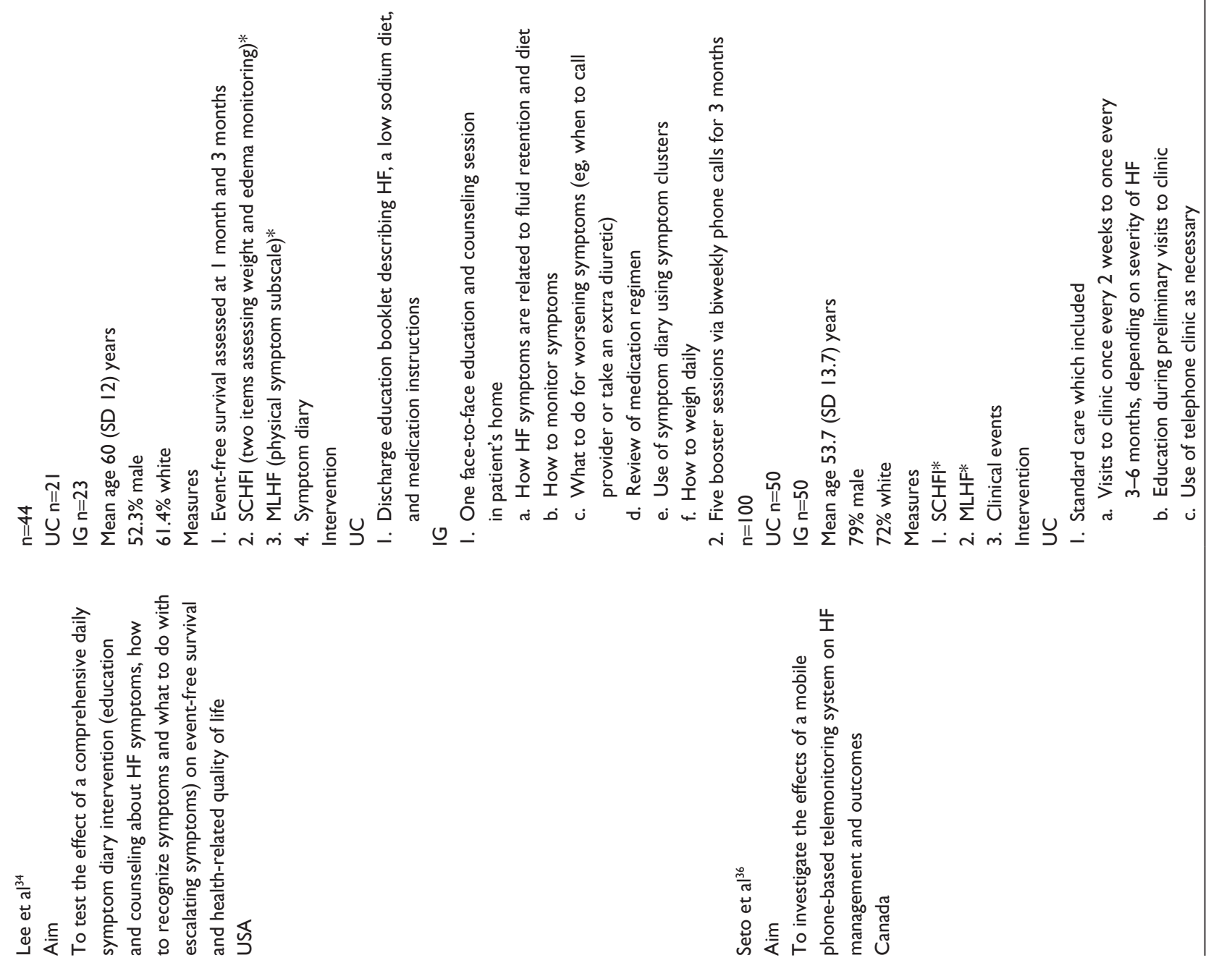




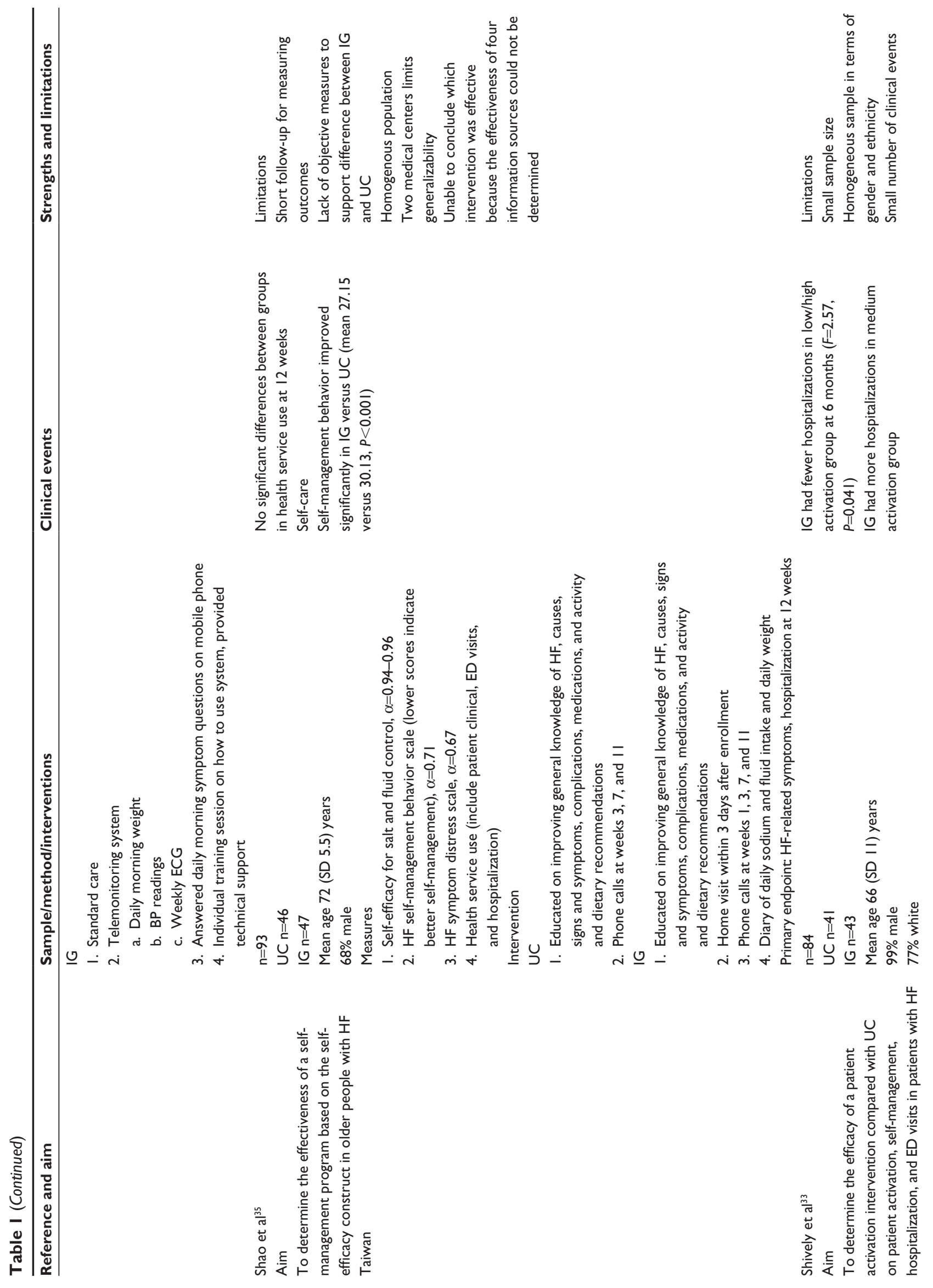



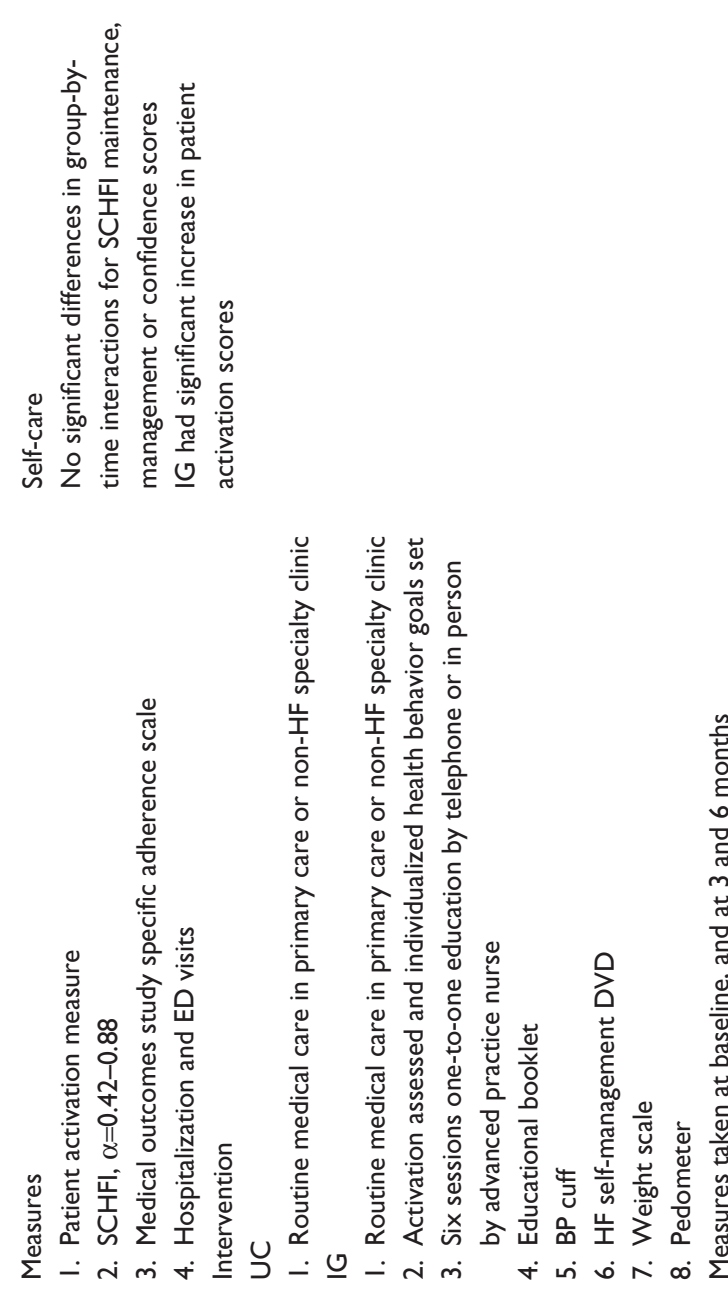

monitor weight, blood pressure, and electrocardiograms for 6 months. ${ }^{36}$ Finally, among investigators using symptom diaries or some form of symptom tracking, ${ }^{7,30,34,35}$ only the study by Lee et al had a significant effect on clinical events. ${ }^{34}$

\section{Self-care interventions and symptom burden}

Symptom burden, as a predictor of quality of life and hospitalization, is an important outcome of interest in relation to the effectiveness of self-care interventions. ${ }^{37,38}$ Symptom burden was reported as an outcome in four studies (Table 2). ${ }^{34-36,39}$ In some cases, measurement was extrapolated from quality of life measures with physical symptom subscales. ${ }^{34,36}$ Two studies reported significant improvement in symptom burden in relation to instituting a self-management intervention. ${ }^{35,39}$

Baker et al compared a brief educational intervention (usual care group) compared with a teach-to-goal intervention on self-care behaviors and HF quality of life. ${ }^{39}$ Both groups received a 40-minute educational session on self-care maintenance and self-care management. All participants $(n=605)$ also received an educational manual and a digital scale. The intervention group was provided with specific instructions on daily weights and diuretic self-adjustment followed by five to eight phone calls over 4 weeks to reinforce the education. The intervention group had significant improvement in symptoms and self-efficacy whereas symptom burden was unchanged in the usual care group. Both groups had significantly improved self-care scores; however, the improvement in the intervention group was significantly greater. Strengths of this study were its large sample size and heterogeneity in terms of gender and ethnicity. Limitations include high baseline HF knowledge and younger mean age than typically found among samples of patients with HF.

The intervention group in the study by Shao et al received the same intervention as the usual care group, supplemented by a home visit, one extra phone call, and a diary for daily sodium, fluid intake, and weight. ${ }^{35}$ Self-care management and symptom scores improved in the intervention group. The intervention by Lee et al was similar; however, the symptom burden did not differ between groups at 3 months. ${ }^{34}$

\section{Discussion}

This review was limited to studies with a self-management component in the intervention. We found the majority of self-care interventions increased knowledge and improved self-care scores, but were inconsistent in relation to decreasing clinical events or reducing symptom burden. The core 

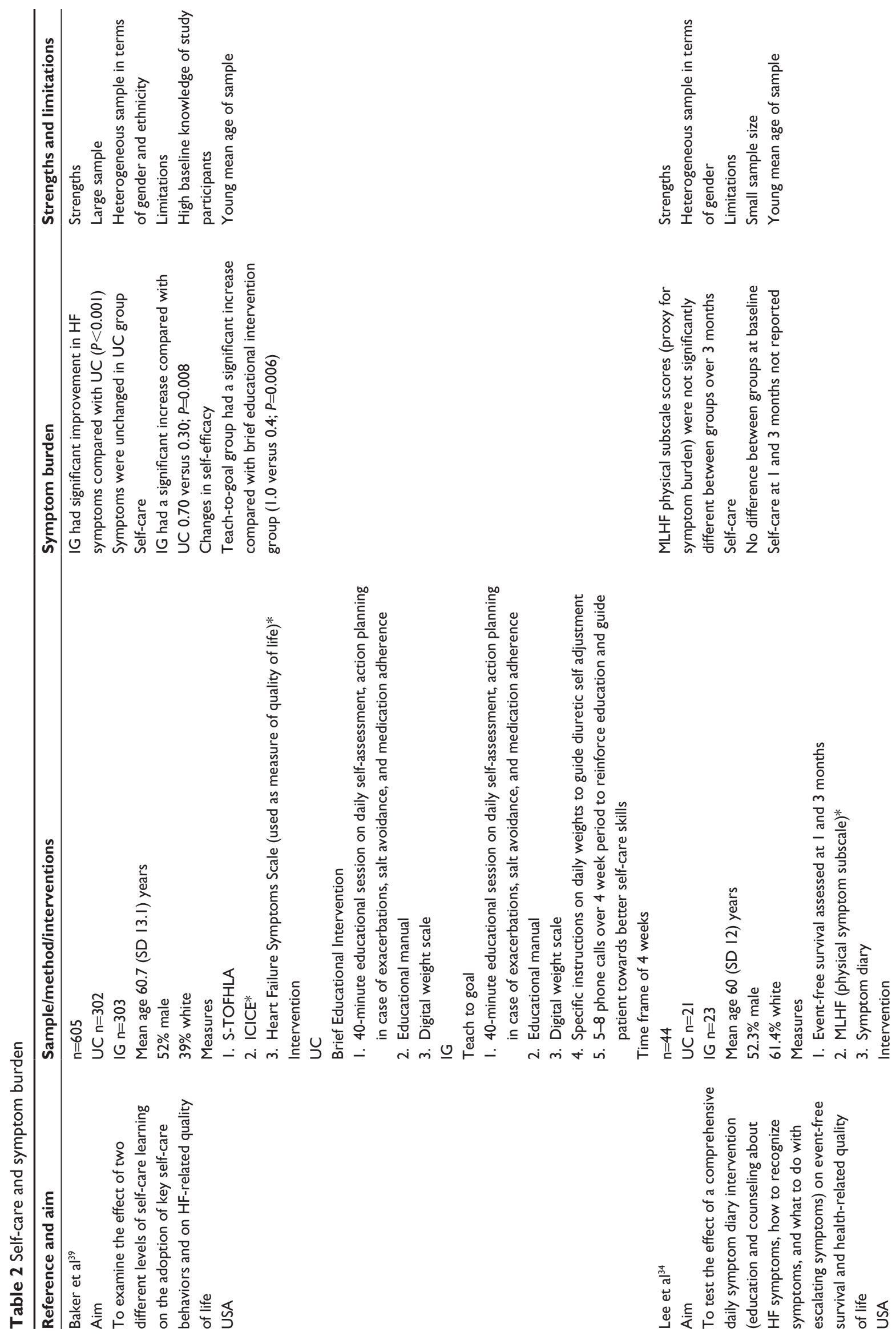

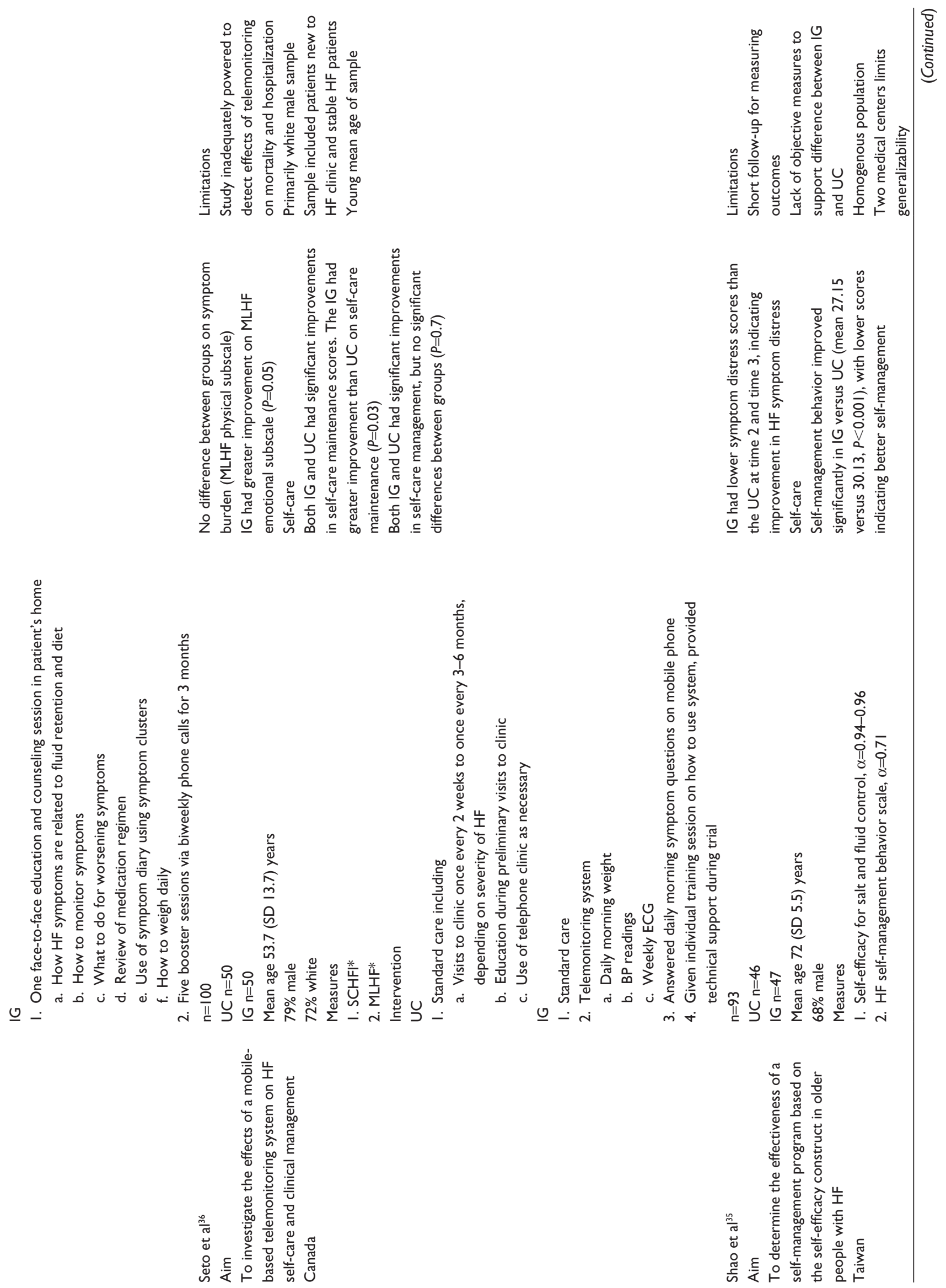


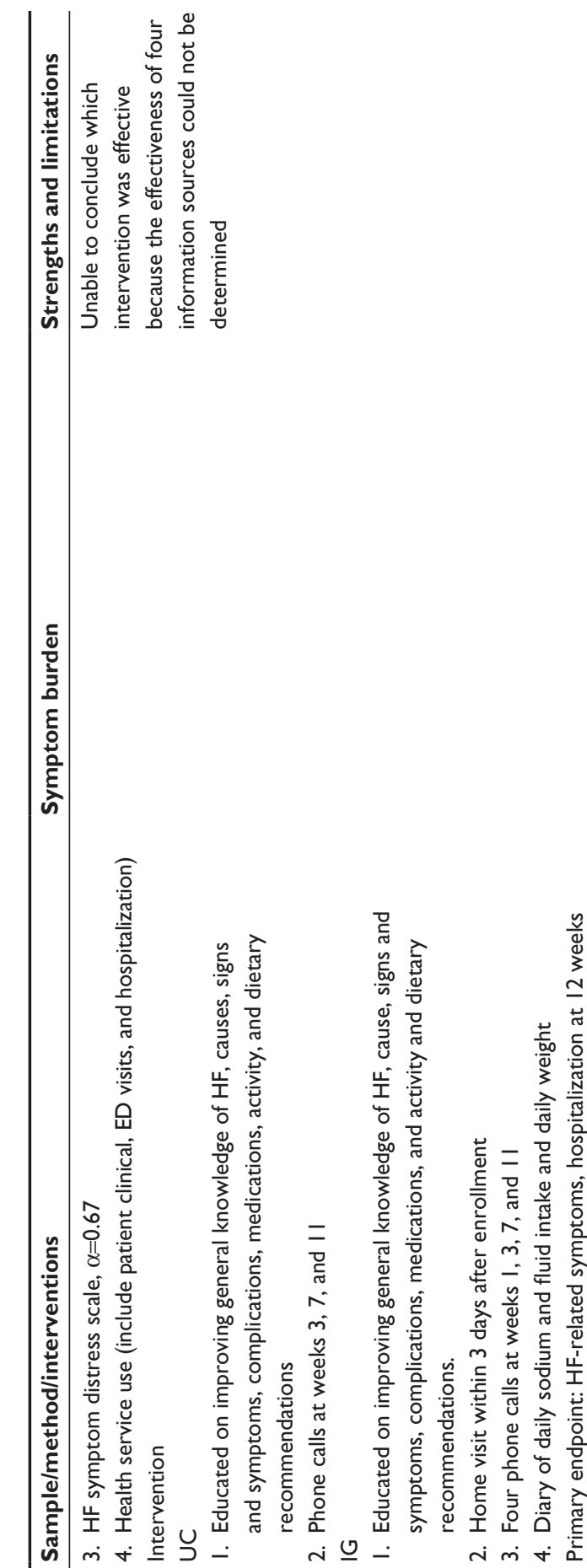

of each intervention was patient education, and educational content was similar across studies. Other components of interventions such as use of symptom diaries or instrumental support (eg, provision of weight scales) also were inconsistent in relation to the outcomes of interest. Only one investigator evaluated the self-care intervention components to identify those that were most effective. Provision of a weight scale and conducting a home visit were the two components associated with statistically significant improved self-care. ${ }^{40}$ Without additional responder analysis data, we are unable to conclusively identify which self-care interventions are most effective in reducing clinical event risk and symptom burden. However, interventions focused on improving skill in symptom monitoring and timely response to escalating symptoms are important. . $^{5,11}$

Self-care, an integral component of HF disease management, is beneficial in terms of reducing morbidity, mortality, and symptom burden, and improving quality of life. ${ }^{41-43}$ Considering HF is a chronic and progressive illness, need for oversight by health care providers will presumably increase over time. However, it is preferable to maximize self-care capacity to assist patients in maintaining clinical stability and independence for as long as possible.

Self-care capacity is known to vary among patients. ${ }^{44}$ Several factors affect self-care capacity, including but not limited to cognitive status, ${ }^{17,18,45}$ health literacy, ${ }^{46,47}$ depression, ${ }^{48-50}$ and self-efficacy or self-confidence. ${ }^{39,51}$ Consequently, determining which self-management interventions are effective for improving outcomes in different populations is challenging. Attention to modifiable factors affecting self-care capacity is therefore warranted. In particular, self-efficacy and self-confidence are important targets for self-management interventions because of a moderating and mediating effect on self-care. Lee et al reported that higher levels of self-care were associated with better health status, but only if self-confidence was high. ${ }^{51}$ A case in point is a lack of difference in clinical events in the study by Jurgens et al. The intervention group had a statistically significant improvement in self-care confidence from baseline to 90 days (from 54.3 to $65.2, P \leq 0.01$ ); however, Self-Care of HF Index scores were below 70, which is the cutoff score considered adequate. ${ }^{7}$ Exploring use of interventions that improve self-efficacy and self-care confidence may support increased effectiveness of many of the interventions currently in use. Motivational interviewing and similar cognitive behavioral interventions may be a useful strategy for increasing confidence and subsequent self-management skills. ${ }^{52,53}$ 
Limitations of studies in this review include both methodological concerns and sampling. Treatment fidelity to ensure consistency in delivery of interventions is an important aspect of research. Only one study specifically reported treatment fidelity procedures. ${ }^{7}$ In other studies, fidelity was implied by delivery of the intervention by the same person ${ }^{31-33,39}$ or not reported. ${ }^{30,34-36}$ Limitations to generalizability of the studies also include small sample sizes, ${ }^{7,30,33,36}$ homogenous samples with respect to ethnicity, ${ }^{7,30,32,33,35,36}$ and limited time to follow-up. ${ }^{30}$ Lastly, reporting instrument reliability coefficients affects the interpretation of study results. Only four of the nine studies ${ }^{7,30,33,35}$ reported reliability coefficients.

\section{Research implications}

This review highlights several implications for future conduct of research on HF self-care interventions. First, differentiating the components of self-care, particularly in relation to maintenance and management, is important. Studies in this review support the usefulness of HF education to improve patient knowledge. However, knowledge alone is insufficient to improve outcomes. Knowledge of self-care maintenance or adherence behaviors plus skill in HF self-management is needed to reduce clinical event risk and symptom burden. The evidence also suggests the importance of self-efficacy and self-confidence for effective self-care management. Second, all interventions evaluated in this review incorporated several components, but little is known about which components are most important. As health care resources are limited, conducting responder analyses would assist in filling gaps in knowledge regarding which component(s) to emphasize in terms of outcomes and cost. Third, self-care capacity and effectiveness of interventions varies across individuals and populations. Therefore, analyses of interventions in relation to their effectiveness in subpopulations are needed to guide choice and dose of interventions. ${ }^{5,44,54}$ Finally, research is needed to examine the effect of self-care on health outcomes important to patients, insurance providers, and health care systems. Outcomes of interest include but are not limited to symptom burden, quality of life, morbidity, mortality, and hospitalization.

\section{Implications for practice}

Self-care is an essential component of HF management, but patient education frequently occurs in the time-limited process of hospital discharge. As a result, self-care interventions need to be standardized and feasible for clinicians across health care settings. ${ }^{55,56}$ Consideration of patient factors such as adequacy of social support, health literacy, cognition, depression, socioeconomic status, and advanced age is also important when choosing an intervention. ${ }^{11,21}$ Importantly, patients with HF seek information on how to negotiate all the components of self-management in addition to understanding medications, dietary restrictions, and symptom monitoring. ${ }^{6}$ Consequently, a focus on skill-building educational tactics is needed in addition to basic self-care information. Timely self-management is challenging for patients due to difficulty in detecting an increase over baseline symptoms. ${ }^{4}$ As a result, delay in seeking care for symptoms is common, because symptoms such as weight gain and increasing fatigue are not perceived as important or related to HF. ${ }^{12,57}$ To support effective self-management, patients need specific instruction on the importance of symptoms and what to do when symptoms occur (eg, weight gain). Inclusion of family members or other support persons in education and skill building is recommended as they can assist with many components of self-care, including detecting a change in status. ${ }^{11}$

\section{Conclusion}

Self-management of HF is a complex proposition for patients and their families based on the skills required to maintain clinical stability as well as skills for symptom management. The most effective dose for self-care interventions is unknown. Strategies that increase self-care confidence may be a key factor in determining the frequency and amount of oversight needed over time. ${ }^{50,51}$ Finally, patients need to understand the importance of acting when a change in status occurs. Patients with HF are known to wait to see if symptoms improve. ${ }^{12}$ Understanding the importance of selfmanagement of the early symptoms of HF, such as weight gain, increasing fatigue, decreasing activity tolerance, and dyspnea on exertion, is particularly important. If the early symptoms of impending decompensation are recognized and treated, hospitalization for symptom management may be averted.

\section{Disclosure}

The authors report no conflicts of interest in this work.

\section{References}

1. Go AS, Mozaffarian D, Roger VL, et al. Heart disease and stroke statistics - 2014 update: a report from the American Heart Association. Circulation. 2014;129:e28-e292.

2. Will JC, Valderrama AL, Yoon PW. Preventable hospitalizations for congestive heart failure: establishing a baseline to monitor trends and disparities. Prev Chronic Dis. 2012;9:E85.

3. Boyde M, Turner C, Thompson DR, Stewart S. Educational interventions for patients with heart failure: a systematic review of randomized controlled trials. J Cardiovasc Nurs. 2011;26:E27-E35. 
4. Horowitz CR, Rein SB, Leventhal H. A story of maladies, misconceptions, and mishaps: effective management of heart failure. Soc Sci Med. 2004;58:631-643.

5. Riegel B, Lee CS, Dickson VV. Self care in patients with chronic heart failure. Nat Rev Cardiol. 2011;8:644-654.

6. Dickson VV, Riegel B. Are we teaching what patients need to know? Building skills in heart failure self-care. Heart Lung. 2009;38: 253-261.

7. Jurgens CY, Lee CS, Reitano JM, Riegel B. Heart failure symptom monitoring and response training. Heart Lung. 2013;42:273-280.

8. Ditewig JB, Blok H, Havers J, van Veenendaal H. Effectiveness of self-management interventions on mortality, hospital readmissions, chronic heart failure hospitalization rate and quality of life in patients with chronic heart failure: a systematic review. Patient Educ Couns. 2010;78:297-315.

9. Riegel B, Dickson VV. A situation-specific theory of heart failure selfcare. J Cardiovasc Nurs. 2008;23:190-196.

10. Riegel B, Lee CS, Dickson VV, Carlson B. An update on the self-care of heart failure index. J Cardiovasc Nurs. 2009;24:485-497.

11. Riegel B, Moser DK, Anker SD, et al. State of the science: promoting self-care in persons with heart failure: a scientific statement from the American Heart Association. Circulation. 2009;120:1141-1163.

12. Jurgens CY, Hoke L, Byrnes J, Riegel B. Why do elders delay responding to heart failure symptoms? Nurs Res. 2009;58:274-282.

13. Dickson VV, Buck H, Riegel B. A qualitative meta-analysis of heart failure self-care practices among individuals with multiple comorbid conditions. J Card Fail. 2011;17:413-419.

14. Cocchieri A, Riegel B, D'Agostino F, et al. Describing self-care in Italian adults with heart failure and identifying determinants of poor self-care. Eur J Cardiovasc Nurs. Epub January 9, 2014.

15. Braunstein JB, Anderson GF, Gerstenblith G, et al. Noncardiac comorbidity increases preventable hospitalizations and mortality among Medicare beneficiaries with chronic heart failure. J Am Coll Cardiol. 2003;42:1226-1233.

16. Mastromarino V, Casenghi M, Testa M, et al. Polypharmacy in heart failure patients. Curr Heart Fail Rep. 2014;11:212-219.

17. Cameron J, Worrall-Carter L, Page K, Riegel B, Lo SK, Stewart S. Does cognitive impairment predict poor self-care in patients with heart failure? Eur J Heart Fail. 2010;12:508-515.

18. Dickson VV, Tkacs N, Riegel B. Cognitive influences on selfcare decision making in persons with heart failure. Am Heart $J$. 2007;154:424-431.

19. Jurgens CY, Faulkner KM, Lee CS. Phenotypic profiling of cognitive impairment risk among patients with heart failure: a literature review of the usefulness of cardiac-related variables. Eur J Cardiovasc Nurs. 2013;12:109-131.

20. Yancy CW, Jessup M, Bozkurt B, et al. 2013 ACCF/AHA guideline for the management of heart failure: a report of the American College of Cardiology Foundation/American Heart Association Task Force on practice guidelines. Circulation. 2013;128:e240-e327.

21. Barnason S, Zimmerman L, Young L. An integrative review of interventions promoting self-care of patients with heart failure. J Clin Nurs. 2012;21:448-475.

22. Jovicic A, Holroyd-Leduc JM, Straus SE. Effects of self-management intervention on health outcomes of patients with heart failure: a systematic review of randomized controlled trials. BMC Cardiovasc Disord. 2006;6:43.

23. Gwadry-Sridhar FH, Arnold JM, Zhang Y, Brown JE, Marchiori G, Guyatt G. Pilot study to determine the impact of a multidisciplinary educational intervention in patients hospitalized with heart failure. $\mathrm{Am}$ Heart J. 2005; 150:982.

24. Laramee AS, Levinsky SK, Sargent J, Ross R, Callas P. Case management in a heterogeneous congestive heart failure population: a randomized controlled trial. Arch Intern Med. 2003;163:809-817.

25. Powell LH, Calvin JE Jr, Richardson D, et al. Self-management counseling in patients with heart failure: the heart failure adherence and retention randomized behavioral trial. JAMA. 2010;304:1331-1338.
26. Sethares KA, Elliott K. The effect of a tailored message intervention on heart failure readmission rates, quality of life, and benefit and barrier beliefs in persons with heart failure. Heart Lung. 2004;33:249-260.

27. Ganong LH. Integrative reviews of nursing research. Res Nurs Health. 1987;10:1-11.

28. Whittemore R. Analysis of integration in nursing science and practice. J Nurs Scholarsh. 2005;37:261-267.

29. Whittemore R, Knafl K. The integrative review: updated methodology. J Adv Nurs. 2005;52:546-553.

30. Davis KK, Mintzer M, Dennison Himmelfarb CR, Hayat MJ, Rotman S, Allen J. Targeted intervention improves knowledge but not self-care or readmissions in heart failure patients with mild cognitive impairment. Eur J Heart Fail. 2012;14:1041-1049.

31. DeWalt DA, Schillinger D, Ruo B, et al. Multisite randomized trial of a single-session versus multisession literacy-sensitive self-care intervention for patients with heart failure. Circulation. 2012;125: 2854-2862.

32. Kommuri NV, Johnson ML, Koelling TM. Relationship between improvements in heart failure patient disease specific knowledge and clinical events as part of a randomized controlled trial. Patient Educ Couns. 2012;86:233-238.

33. Shively MJ, Gardetto NJ, Kodiath MF, et al. Effect of patient activation on self-management in patients with heart failure. J Cardiovasc Nurs. 2013;28:20-34.

34. Lee KS, Lennie TA, Warden S, Jacobs-Lawson JM, Moser DK. A comprehensive symptom diary intervention to improve outcomes in patients with HF: a pilot study. J Card Fail. 2013;19:647-654.

35. Shao JH, Chang AM, Edwards H, Shyu YI, Chen SH. A randomized controlled trial of self-management programme improves health-related outcomes of older people with heart failure. J Adv Nurs. 2013;69: 2458-2469.

36. Seto E, Leonard KJ, Cafazzo JA, Barnsley J, Masino C, Ross HJ. Mobile phone-based telemonitoring for heart failure management: a randomized controlled trial. J Med Internet Res. 2012;14:e31.

37. Gott M, Barnes S, Parker C, et al. Predictors of the quality of life of older people with heart failure recruited from primary care. Age Ageing. 2006;35:172-177.

38. Heo S, Doering LV, Widener J, Moser DK. Predictors and effect of physical symptom status on health-related quality of life in patients with heart failure. Am J Crit Care. 2008;17:124-132.

39. Baker DW, Dewalt DA, Schillinger D, et al. The effect of progressive, reinforcing telephone education and counseling versus brief educational intervention on knowledge, self-care behaviors and heart failure symptoms. J Card Fail. 2011;17:789-796.

40. Jurgens CY, Riegel B. Improving heart failure self-care: a responder analysis of an educational intervention. Nurs Res. 2013;62:E25.

41. Lainscak M, Blue L, Clark AL, et al. Self-care management of heart failure: practical recommendations from the Patient Care Committee of the Heart Failure Association of the European Society of Cardiology. Eur J Heart Fail. 2011;13:115-126.

42. Wang SP, Lin LC, Lee CM, Wu SC. Effectiveness of a self-care program in improving symptom distress and quality of life in congestive heart failure patients: a preliminary study. J Nurs Res. 2011;19:257-266.

43. Lee CS, Moser DK, Lennie TA, Riegel B. Event-free survival in adults with heart failure who engage in self-care management. Heart Lung. 2011;40:12-20.

44. Dickson VV, Deatrick JA, Riegel B. A typology of heart failure self-care management in non-elders. Eur J Cardiovasc Nurs. 2008;7:171-181.

45. Dickson VV, Lee CS, Riegel B. How do cognitive function and knowledge affect heart failure self-care? J Mixed Methods Res. 2011;5:167-189.

46. Chen AM, Yehle KS, Plake KS, Murawski MM, Mason HL. Health literacy and self-care of patients with heart failure. J Cardiovasc Nurs. 2011;26:446-451.

47. Dennison CR, McEntee ML, Samuel L, et al. Adequate health literacy is associated with higher heart failure knowledge and self-care confidence in hospitalized patients. J Cardiovasc Nurs. 2011;26:359-367. 
48. Dickson VV, McCarthy MM, Katz SM. How do depressive symptoms influence self-care among an ethnic minority population with heart failure? Ethn Dis. 2013;23:22-28.

49. Johnson TJ, Basu S, Pisani BA, et al. Depression predicts repeated heart failure hospitalizations. J Card Fail. 2012;18:246-252.

50. Maeda U, Shen BJ, Schwarz ER, Farrell KA, Mallon S. Self-efficacy mediates the associations of social support and depression with treatment adherence in heart failure patients. Int J Behav Med. 2013;20:88-96.

51. Lee CS, Suwanno J, Riegel B. The relationship between self-care and health status domains in Thai patients with heart failure. Eur $J$ Cardiovasc Nurs. 2009;8:259-266.

52. Paradis V, Cossette S, Frasure-Smith N, Heppell S, Guertin MC. The efficacy of a motivational nursing intervention based on the stages of change on self-care in heart failure patients. J Cardiovasc Nurs. 2010;25:130-141.
53. Peters-Klimm F, Freund T, Kunz CU, et al. Determinants of heart failure self-care behaviour in community-based patients: a cross-sectional study. Eur J Cardiovasc Nurs. 2013;12:167-176.

54. Harkness K, Spaling MA, Currie K, Strachan PH, Clark AM. A systematic review of patient heart failure self-care strategies. J Cardiovasc Nurs. Epub March 18, 2014.

55. Koelling TM, Johnson ML, Cody RJ, Aaronson KD. Discharge education improves clinical outcomes in patients with chronic heart failure. Circulation. 2005;111:179-185.

56. Riegel B, Carlson B, Kopp Z, LePetri B, Glaser D, Unger A. Effect of a standardized nurse case-management telephone intervention on resource use in patients with chronic heart failure. Arch Intern Med. 2002;162:705-712.

57. Jurgens CY. Somatic awareness, uncertainty, and delay in care-seeking in acute heart failure. Res Nurs Health. 2006;29:74-86.

\section{Publish your work in this journal}

Research Reports in Clinical Cardiology is an international, peerreviewed, open access journal publishing original research, reports, editorials, reviews and commentaries on all areas of cardiology in the clinic and laboratory. The manuscript management system is completely online and includes a very quick and fair peer-review system.
Visit http://www.dovepress.com/testimonials.php to read real quotes from published authors. 